\title{
Effectiveness of a discharge planning and community support programme in preventing readmission of high-risk older patients
}

\author{
Francis OY Lin, James KH Luk *, TC Chan, Winnie WY Mok, Felix HW Chan
}

\section{A B S T R A C T}

Objective: To examine the effectiveness of Integrated Care and Discharge Support for elderly patients in reducing accident and emergency department attendance, acute hospital admissions, and hospital bed days after discharge. Factors that compromise its effectiveness were investigated and cost analysis was performed.

Design: Cohort prospective study.

Setting: Integrated Care and Discharge Support for elderly patients in Hong Kong West Cluster.

Participants: Home-dwelling patients recruited between April 2012 and March 2013 into Integrated Care and Discharge Support for elderly patients in Hong Kong West Cluster.

Results: A total of 1090 older patients were studied. The Integrated Care and Discharge Support for elderly patients programme reduced accident and emergency department attendance by $40 \%$ $(\mathrm{P}<0.001)$, acute hospital admissions by $47 \%$ $(\mathrm{P}<0.001)$, and hospital bed days by $31 \%(\mathrm{P}<0.001)$ at 6 months after implementation. Improvements in Barthel Index $20(\mathrm{P}<0.001)$ and Modified Functional Ambulation Category scale $(\mathrm{P}<0.001)$ were observed. Of the patients, $85(7.8 \%)$ died within 6 months of initiation of the programme. Only 26 (2.4\%) older patients required institutionalisation in residential care homes within 6 months after the programme. Increasing age $(\mathrm{P}=0.025)$ and high Charlson Comorbidity Index score $(\mathrm{P}=0.001)$ were positive predictors for accident and emergency department attendance. A high albumin level $(\mathrm{P}=0.001)$ and accident and emergency department attendance. Of the patients, $310(28.4 \%)$ had no reduction in bed days after the programme. Increasing age $(\mathrm{P}=0.025)$ and number of medications $(\mathrm{P}=0.003)$ were positive predictors for no reduction in bed days; while higher haemoglobin level $(\mathrm{P}=0.034)$ was a negative predictor. There was a potential annual cost-saving of HK\$22.5 million (approximately US\$2.9 million).

Conclusion: The Integrated Care and Discharge Support for elderly patients programme reduced accident and emergency department attendance, acute hospital admissions and hospital bed days, and was potentially cost-saving. Age, Charlson Comorbidity Index, albumin level, and living alone were factors associated with accident and emergency department attendance. Age, number of medications, and haemoglobin level were associated with no reduction in bed days. Further study of the cost-effectiveness of such programme is warranted.

\section{Hong Kong Med J 2015;21:208-16 \\ DOI: $10.12809 / \mathrm{hkmj} 144304$}

FOY Lin, MB, BS, MRCP (UK)

JKH Luk *, FHKCP, FHKAM (Medicine)

TC Chan, FHKCP, FHKAM (Medicine)

WWY Mok, FHKCP, FHKAM (Medicine)

FHW Chan, FHKCP, FHKAM (Medicine)

Department of Medicine and Geriatrics, TWGHs Fung Yiu King Hospital, 9 Sandy Bay Road, Pokfulam, Hong Kong

* Corresponding author: lukkh@ha.org.hk

New knowledge added by this study

- Integrated Care and Discharge Support for elderly patients (ICDS) reduced accident and emergency department (AED) attendances, acute hospital admissions, and hospital bed days.

- ICDS service was potentially cost-saving and might minimise institutionalisation.

- Age, Charlson Comorbidity Index, albumin level, and living alone were associated with AED attendance.

- Age, number of medications, and haemoglobin levels were associated with no reduction in bed days.

Implications for clinical practice or policy

- ICDS programme should be continued in Hong Kong to face the challenges of an increasing older population.

- Further studies are suggested to examine whether AED attendance, acute hospital admissions, and hospital bed days among high-risk older patients can be further reduced by modifying some of the predictive factors identified in this study.

- A more detailed auditing is warranted to show its value in reducing health care costs. 


\section{Introduction}

'Revolving door syndrome' was a phrase coined by Gordon ${ }^{1}$ in 1995 to describe the problem of recurrent return of older people to hospital shortly after discharge. Readmission is common among medical patients, especially the elderly population, and is a poor outcome for the health care system., ${ }^{2,3}$ A retrospective analysis in 2007 showed the overall 30-day unplanned readmission rate of medical patients was $16.7 \% .^{4}$ A study in Hong Kong West Cluster (HKWC) showed the 28-day readmission rate for elderly patients discharged from a geriatric convalescent hospital to be $21.6 \%{ }^{5}$

To date, different programmes and strategies have been described to reduce hospital readmission. These include comprehensive geriatric assessment, discharge planning, adopting a case manager approach, post-discharge support services, early intervention for ad-hoc medical problems, and use of telephone nursing services. ${ }^{6-11}$ It has been advocated that in order to achieve better efficacy, any programme that aims to prevent hospital readmission should focus on patients at high risk. ${ }^{12}$ In Hong Kong, the Hospital Authority (HA) has developed a validated prediction model named "Hospital Admission Risk Reduction Program for the Elderly" (HARRPE) to identify older people at high risk of readmissions. ${ }^{13}$ The HARRPE score comprises 14 predictors that are categorised into socio-demographic data, prior utilisation of accident and emergency department (AED) and medical ward admission in the past 1 year, co-morbidity, and current index admission. The higher the HARRPE score (ranges from 0 to 1 ), the higher the readmission risk.

In Hong Kong, a pilot Integrated Discharge Support Program for Elderly Patients (IDSP) was launched in three hospitals, namely the United Christian Hospital in 2008, Princess Margaret Hospital in 2008, and Tuen Mun Hospital in 2009. The programme targeted patients aged $\geq 60$ years admitted to these hospitals with a HARRPE score of $\geq 0.2$. It aimed to reduce the risk of AED attendance and hospital readmission through better discharge planning and post-discharge support. Preliminary results showed it successfully reduced AED attendance, emergency admission, and hospital bed days. ${ }^{14}$

In view of the positive results of IDSP and based on the recommendation of the Elderly Commission, the Financial Secretary of the Hong Kong SAR announced in the 2011/2012 budgets that the Government would allocate additional recurrent funding to make it a regular service to all districts. In addition, a new case management approach, Integrated Care Model (ICM), was added. Such new programme has been renamed Integrated Care and Discharge Support for elderly patients (ICDS).

\section{預防高危年長病人再次入院的「支援長者離院 綜合服務」的成效 \\ 連靁怡、陸嘉熙、陳端正、莫穎儀、陳漢威}

目的：探討年長病人離院後, 「支援長者離院綜合服務」對於減低他 們再次到急症室求診、緊急入院比率和住院日數的成效。研究並研究 影響其成效的因素, 以及進行成本分析。

設計：隊列前瞻性研究。

安排：香港港島西醫院聯網的「支援長者離院綜合服務」。

參與者：於 2012 年4月至2013年3月期間參與香港港島西醫院聯網 「支援長者離院綜合服務」並居住於家中的年長病人。

結果：共1090名年長病人參與本研究。參加了「支援長者離院綜合 服務」6個月後, 到急症室求診的比率減少了 $40 \%(\mathrm{P}<0.001)$ 緊急入院的比率減少了 $47 \%(\mathrm{P}<0.001)$ ，住院日數亦減少了 $31 \%$ $(\mathrm{P}<0.001) \circ$ Barthel 20指數 $(\mathrm{P}<0.001)$ 和改良功能步行狀況 分類量表分數 $(\mathrm{P}<0.001)$ 均有改善。為期 6 個月的計劃期間共 85 人 $(7.8 \%)$ 死亡, 並有 26 人 $(2.4 \%)$ 入住安老院舍。年齡較大 $(\mathrm{P}=0.025)$ 和Charlson合併症指數高 $(\mathrm{P}=0.001)$ 均為急症室求診的 陽性預測因素 ; 而高蛋白水平 $(\mathrm{P}=0.001)$ 和獨居 $(\mathrm{P}=0.033)$ 則為其 陰性預測因素。3 10 人 ( $28.4 \%)$ 在參加支援計劃後的住院日數未見減 少。年齡較大 $(\mathrm{P}=0.025)$ 和服用藥物數量較多者 $(\mathrm{P}=0.003)$ 均為住 院日數無減少的陽性預測因素; 而較高的血紅蛋白水平（ $\mathrm{P}=0.034 ）$ 則為其陰性預測因素。「支援長者離院綜合服務」每年潛在節省的費 用為港幣2250萬（即約290萬美元）。

結論：「支援長者離院綜合服務」能減低年長病人到急症室求診、緊 急入院的比率和住院日數, 並能潛在節省成本。年齡、Charlson合併 症指數、蛋白水平和獨居均與急症室求診的比率相關。年齡、服用藥 物數量和血紅蛋白水平則與住院日數無減少相關。研究認為須進一步 研究「支援長者離院綜合服務」的成本效益。

\section{Integrated Care and Discharge Support for elderly patients in Hong Kong West Cluster}

In January 2012, HKWC launched the ICDS and involves hospital and community components (Fig). For the hospital component, risk stratification, comprehensive geriatric assessment, and discharge planning are performed. Link nurses (who serve as 'link' between in-patients and community services) work with geriatricians to perform multidimensional assessments for home-dwelling older patients aged $\geq 60$ years admitted to medical wards with HARRPE score of $\geq 0.2$. They also assess elderly patients by proactive screening. In addition, patients can be referred to link nurses using a standardised clinical referral form. The form can be completed by any member of the clinical team, including doctors, nurses, pharmacists, and any allied health care professional. The criteria for clinical referral include items such as frequent readmission, poor social support, inadequate care at home, deterioration in memory, drug compliance problems, repeated 


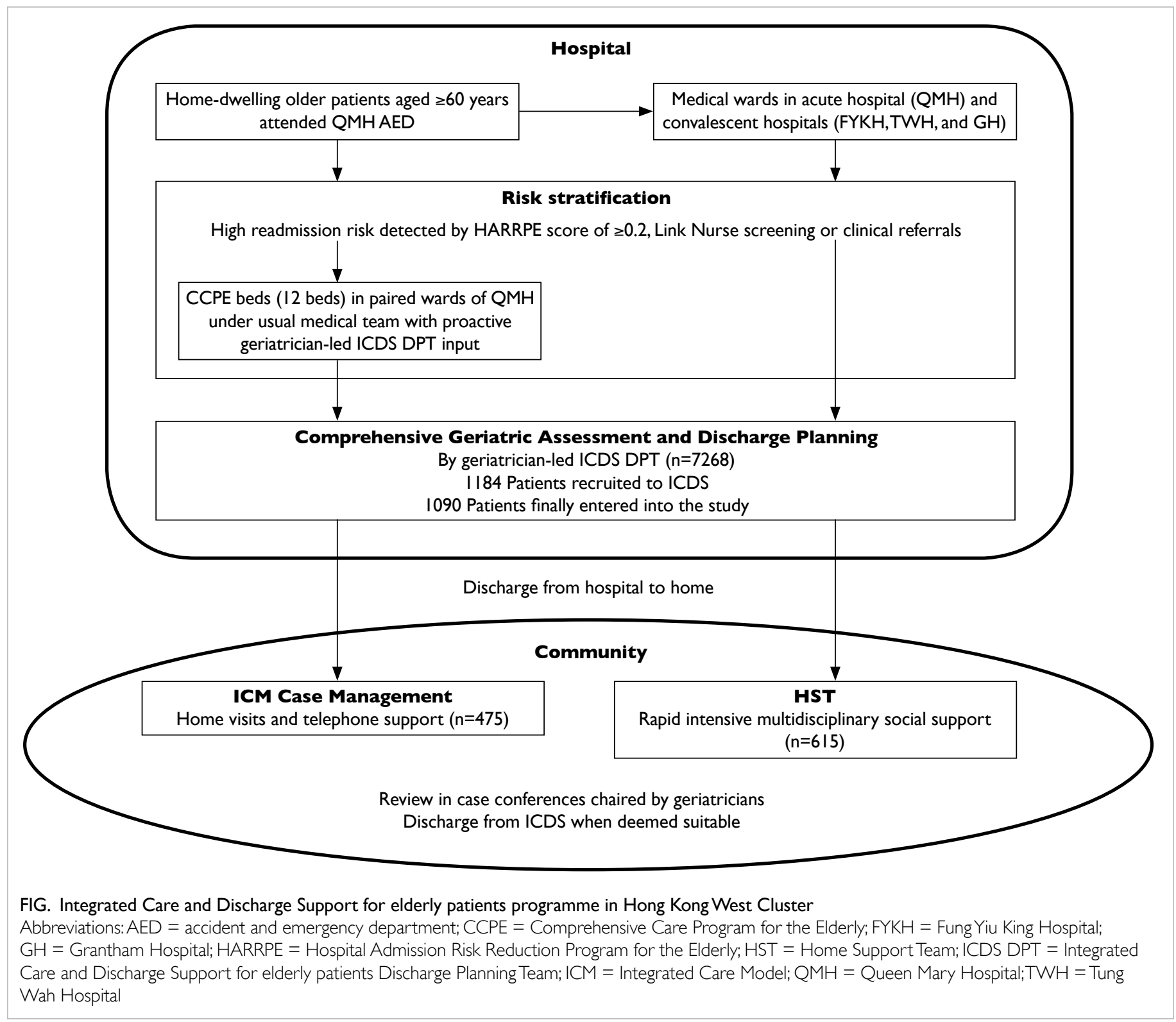

falls, mobility, and functional impairment. Referrers can also comment about any problem not listed in the referral form. In HKWC, case recruitment and discharge planning take place in the medical wards of the acute hospital, Queen Mary Hospital $(\mathrm{QMH})$, and three convalescent hospitals, namely the Fung Yiu King Hospital (FYKH), Grantham Hospital (GH), and Tung Wah Hospital (TWH). After assessment, link nurses will, according to need, allocate patients to either ICM Case Management or Home Support Team (HST) services (see below). In order to enhance the care of high-risk older patients in QMH, a Comprehensive Care Program for the Elderly (CCPE) area has been established. There are 12 beds designated as CCPE ( 6 male and 6 female beds) in paired wards of QMH. Case recruitment for CCPE is mainly from the AED. Patients in CCPE are under the care of the regular medical team with proactive ICDS multidisciplinary input including geriatric assessment and discharge planning for appropriate community support services.

In the community component, there are two important streams, namely the ICM Case Management and HST service. In ICM Case Management, each high-risk older patient is followed up by a case manager for a period of around 3 months following hospital discharge. In HKWC, in terms of full-time equivalence, two social workers, one physiotherapist (PT), one occupational therapist $(\mathrm{OT})$, and half a nurse (advanced practice nurse) take turns to be a case manager. Case managers provide post-discharge support to older patients by home visits and telephone support. They are responsible for community service coordination and ensuring 
patient compliance with planned services and management. The second stream is the HST service and is the responsibility of a non-governmental organisation (NGO) partner. In HKWC, the NGO partner is Aberdeen Kai-fong Association (香港仔坊 會). This HST includes nurses, PT, OT, and other allied health members. They provide rapid and intensive community support for discharged patients, offering services such as meal delivery, household cleaning, respite care, and home assessment and modification.

Case selection and allocation to ICM Case Management or HST is performed by link nurses under the supervision of an ICM geriatrician. Link nurses apply standardised selection criteria for case allocation. In general, patients with more complex medical and social problems who require multidisciplinary intervention by nurses, PT, and/ or OT will be allocated to ICM Case Management. Those who require urgent social services are recruited into HST. Link nurses, ICM case managers, and the HST hold weekly multidisciplinary case conferences chaired by an ICM geriatrician. If needed, referral for rehabilitation in a geriatric day hospital, fast track clinic, or early specialist clinic follow-up can be offered to patients.

\section{Knowledge gaps}

The ICDS programme that started in HKWC in 2012 is unprecedented and deserves a large-scale study to demonstrate its efficacy. Although the aim of ICDS is not to reduce costs, its value and sustainability can nonetheless be better justified if this can be achieved.

The objectives of this prospective cohort study were to investigate whether the ICDS can reduce AED attendance, acute hospital admissions, and hospital bed days (acute and convalescence), and to identify the independent factors that predict its efficacy. In addition, we wished to determine whether there is potential for ICDS to reduce health care costs.

\section{Methods}

\section{Design and setting}

This was a prospective cohort study performed in four hospitals of HKWC, namely the QMH, FYKH, $\mathrm{GH}$, and TWH. The study protocol was approved by the Institutional Review Boards of the University of Hong Kong and HA HKWC.

\section{Subjects}

Our subjects were home-dwelling older patients aged $\geq 60$ years admitted to the general medical wards of QMH and were recruited into the ICDS programme by link nurses from 1 April 2012 to 30 March 2013. Patients were excluded from the analysis if they died, entered residential care homes for the elderly (RCHEs), moved out of the cluster, or refused ICDS services before their first home visit.

\section{Variables}

Baseline data included demography, HARRPE score (if available), mode of feeding, continence status, presence of pressure sores, and use of an indwelling urinary catheter, nasogastric tube, or long-term oxygen. The chief problems at index admission of ICDS recruitment were noted. In addition, data on co-morbidities, number of medications, and baseline blood tests including haemoglobin, albumin, and creatinine levels were retrieved from the HA Clinical Management System (CMS). The Charlson Comorbidity Index (CCI) was used to quantify the burden of co-morbid diseases, ${ }^{15}$ and quantified according to International Classification of Diseases (ICD) coding in CMS.

Cognitive status was assessed on entry to and discharge from the ICDS programme using the Abbreviated Mental Test (AMT). ${ }^{16}$ The patients' Modified Functional Ambulation Category scale (MFAC) and Barthel Index 20 (BI-20) status were also recorded. ${ }^{17}$ The mortality rate and institutionalisation rate of patients within 6 months of intake were calculated.

\section{Outcome measurement}

We compared the number of AED attendances, unplanned acute hospital admissions, and length of stay (LOS) in both acute and convalescent hospitals 6 months before and 6 months after recruitment. The index AED attendance and hospital admissions were counted as pre-6-month outcome. Any subsequent AED attendance and hospital admission was included in the post-6-month data. Two specific outcomes were identified, namely any AED attendance 6 months after ICDS recruitment, and no reduction in hospital bed days (acute and convalescence) 6 months after ICDS. The potential cost-saving of ICDS was calculated using the existing cost of AED attendances as well as bed day cost in acute and convalescent hospitals in HKWC.

\section{Statistical analyses}

The Statistical Package for the Social Sciences (Windows version 18.0; SPSS Inc, Chicago [IL], US) was used in statistical analysis. Continuous variables were expressed as mean \pm standard deviation. Independent $t$ test was used to compare continuous variables of two different groups. Paired $t$ test was used to compare the continuous variables within groups. Mann-Whitney test and Wilcoxon signed rank test were used when the continuous variables could not be assumed to be in normal distribution. Chi squared test and Fisher's exact test were employed to compare categorical variables. The association between different variables with any AED attendance and no reduction in bed days was calculated using univariate logistic regression. 
TABLE I. Baseline characteristics of studied subjects

\begin{tabular}{|c|c|c|c|c|}
\hline \multirow[t]{2}{*}{ Characteristic } & \multicolumn{3}{|c|}{ Mean \pm SD or No. (\%) } & \multirow{2}{*}{$\begin{array}{c}\text { P value } \\
\text { (HARRPE vs } \\
\text { non-HARRPE) }\end{array}$} \\
\hline & All patients $(n=1090)$ & $\begin{array}{l}\text { HARRPE patients } \\
(n=339)\end{array}$ & $\begin{array}{l}\text { Non-HARRPE patients } \\
\text { recruited by clinical } \\
\text { referral or screening } \\
(n=751)\end{array}$ & \\
\hline Age (years) & $80.4 \pm 7.6$ & $81.7 \pm 7.5$ & $79.7 \pm 7.5$ & $<0.001$ \\
\hline Male & $533(48.9)$ & $214(63.1)$ & $319(42.5)$ & $<0.001$ \\
\hline Caring situation & & & & $<0.001$ \\
\hline Live alone & $154(14.1)$ & $27(8.0)$ & $127(16.9)$ & \\
\hline Live with maid & $24(2.2)$ & $10(3.0)$ & $14(1.9)$ & \\
\hline Live with first-degree relative(s) & $698(64.0)$ & $225(66.4)$ & $473(63.0)$ & \\
\hline Live with first-degree relative(s) and maid & $205(18.8)$ & $72(21.2)$ & $133(17.7)$ & \\
\hline Live with friend(s) & $9(0.8)$ & $5(1.4)$ & $4(0.5)$ & \\
\hline Daytime alone & $322(29.6)$ & $72(21.2)$ & $250(33.2)$ & $<0.001$ \\
\hline Financial support & & & & 0.067 \\
\hline Depends on family/saving/OAA/OALA & $900(82.6)$ & $265(78.2)$ & $635(84.6)$ & \\
\hline Normal disability allowance & $69(6.3)$ & $28(8.3)$ & $41(5.5)$ & \\
\hline High disability allowance & $7(0.6)$ & $1(0.3)$ & $6(0.8)$ & \\
\hline Comprehensive Social Security Assistance & $114(10.5)$ & $45(13.2)$ & $69(9.2)$ & \\
\hline \multicolumn{5}{|l|}{ Nursing care } \\
\hline Tube feeding & $8(0.7)$ & $6(1.7)$ & $2(0.3)$ & 0.34 \\
\hline Foley catheter & $20(1.8)$ & $10(3.0)$ & $10(1.3)$ & 0.26 \\
\hline Wound & $20(1.8)$ & $16(4.7)$ & $4(0.5)$ & 0.19 \\
\hline Home oxygen & $43(3.9)$ & $34(9.9)$ & $9(1.2)$ & $<0.001$ \\
\hline \multicolumn{5}{|l|}{ Laboratory results } \\
\hline Haemoglobin level (g/L) & $120 \pm 20$ & $116 \pm 21$ & $123 \pm 46$ & $<0.001$ \\
\hline Serum albumin level (g/L) & $37.4 \pm 5.5$ & $35.3 \pm 5.5$ & $38.2 \pm 5.2$ & $<0.001$ \\
\hline Serum creatinine level $(\mu \mathrm{mol} / \mathrm{L})$ & $114.5 \pm 93.1$ & $133.0 \pm 102.8$ & $105.4 \pm 83.8$ & $<0.001$ \\
\hline Total No. of medications & $6.3 \pm 3.4$ & $7.7 \pm 3.3$ & $5.7 \pm 3.2$ & $<0.001$ \\
\hline Charlson Comorbidity Index & $2.4 \pm 3.9$ & $3.3 \pm 2.3$ & $3.1 \pm 4.2$ & $<0.001$ \\
\hline Chief problems at index admission of ICDS recruitment & & & & $<0.001$ \\
\hline Chest infection & $171(15.7)$ & $60(17.7)$ & $111(14.8)$ & \\
\hline Cardiovascular diseases other than heart failure & $132(12.1)$ & $38(11.2)$ & $94(12.5)$ & \\
\hline Sepsis other than chest infection & $128(11.7)$ & $29(8.6)$ & $99(13.2)$ & \\
\hline Chronic obstructive pulmonary disease/asthma & $118(10.8)$ & $76(22.4)$ & $42(5.6)$ & \\
\hline Falls & $109(10.0)$ & $16(4.7)$ & $93(12.4)$ & \\
\hline Heart failure & $79(7.2)$ & $41(12.1)$ & $38(5.1)$ & \\
\hline Musculoskeletal diseases & $64(5.9)$ & $13(3.8)$ & $51(6.8)$ & \\
\hline Stroke & $56(5.1)$ & $10(2.9)$ & $46(6.1)$ & \\
\hline Diabetes mellitus & $56(5.1)$ & $12(3.5)$ & $44(5.9)$ & \\
\hline Dizziness & $50(4.6)$ & $45(13.3)$ & $5(0.7)$ & \\
\hline Gastro-intestinal problems & $39(3.6)$ & $15(4.4)$ & $24(3.2)$ & \\
\hline Syncope & $34(3.1)$ & $28(8.3)$ & $6(0.8)$ & \\
\hline Malignancy & $30(2.8)$ & $19(5.6)$ & $11(1.5)$ & \\
\hline Renal diseases & $20(1.8)$ & $9(2.7)$ & $11(1.5)$ & \\
\hline Dementia & $16(1.5)$ & $3(0.9)$ & $13(1.7)$ & \\
\hline Parkinsonism & $6(0.6)$ & $2(0.6)$ & $4(0.5)$ & \\
\hline Endocrine diseases except diabetes mellitus & $3(0.3)$ & $2(0.6)$ & $1(0.1)$ & \\
\hline
\end{tabular}

Abbreviations: HARRPE = Hospital Admission Risk Reduction Program for the Elderly; ICDS = Integrated Care and Discharge Support for elderly patients; OAA = Old Age Allowance; OALA = Old Age Living Allowance; SD = standard deviation 
The variables were gender, programmes entered, use of home oxygen, use of tube feeding, use of a Foley catheter, presence of wound, BI-20, AMT, MFAC, CCI, haemoglobin level, albumin level, creatinine level, and number of medications. Significant factors detected during univariate analysis were put into multivariate stepwise backward logistic regression. Statistical significance was inferred by a two-tailed P value of 0.05 .

\section{Results}

From 1 April 2012 to 30 March 2013, among 7268 hospital discharges, 1184 (16.3\%) home-dwelling older patients aged $\geq 60$ years were recruited to the ICDS in HKWC. Of these patients, 23 died, 32 were institutionalised, and 39 refused to join the ICDS

TABLE 2. Details of programme entered by subjects

\begin{tabular}{lr}
\hline & No. (\%) or mean \pm SD \\
\hline Source of referral & \\
\hline HARRPE score $\geq 0.2$ & $339(31.2)$ \\
\hline Clinical referral or screening & $751(68.8)$ \\
\hline Programme entered & \\
\hline ICM case management & $475(43.6)$ \\
\hline IDSP HST & $615(56.4)$ \\
\hline ICM case manager & \\
\hline Nurse & $84(17.7)$ \\
\hline Physiotherapist & $106(22.3)$ \\
\hline Occupational therapist & $99(20.8)$ \\
\hline Social worker & $205(43.2)$ \\
\hline Duration of services (days) & \\
\hline ICM case management & $101.5 \pm 38.9$ \\
\hline IDSP HST & $55.9 \pm 12.1$ \\
\hline Whole group & $75.8 \pm 35.4$ \\
\hline
\end{tabular}

Abbreviations: HARRPE = Hospital Admission Risk Reduction Program for the Elderly; ICM = Integrated Care Model; IDSP HST = Integrated Discharge Support Program for Elderly Patients Home Support Team; SD = standard deviation before the first home visit. A total of 1090 patients entered into the study. The baseline characteristics, demography, CCI, and chief problems at index admission of ICDS recruitment are shown in Table 1. Details of the programme entered are shown in Table 2. Table 3 illustrates the change in AED attendances, acute hospital admissions, and bed days (acute and convalescent hospitals) after joining the ICDS. Within 6 months of ICDS service, 85 (7.8\%) patients died and only 26 (2.4\%) older patients required institutionalisation in $\mathrm{RCHEs}$. We observed a $40 \%$ reduction in AED attendances 6 months after initiation of the ICDS compared with 6 months before (mean, 1.2 vs 2.0 episodes; $\mathrm{P}<0.001$ ). There was also a $47 \%$ reduction in acute hospital admissions (mean, 0.9 vs 1.7 episodes; $\mathrm{P}<0.001$ ), and a $31 \%$ reduction in bed days (acute and convalescence) [mean, $11.1 \mathrm{vs}$ 16.1 days; $\mathrm{P}<0.001] 6$ months after joining the ICDS (Table 3).

There was mild improvement in MFAC and BI-20 on discharge from the ICDS compared with the level at entry (MFAC, $6.3 \pm 2.2$ vs $5.7 \pm 1.6$, $\mathrm{P}<0.001$; BI-20, $17.6 \pm 4.1$ vs $16.5 \pm 4.1, \mathrm{P}<0.001)$. There was no significant change in AMT $(8.4 \pm 1.7$ vs $8.4 \pm 2.1 ; \mathrm{P}=0.831)$.

Among 1090 subjects included, 596 (54.7\%) required AED attendance within 6 months of joining the ICDS. Increasing age (odds ratio $[\mathrm{OR}]=1.019$; 95\% confidence interval $[\mathrm{CI}], 1.002-1.036 ; \mathrm{P}=0.025)$ and high $\mathrm{CCI}$ score $(\mathrm{OR}=1.178$; 95\% CI, 1.108-1.254; $\mathrm{P}=0.001$ ) were independent positive predictors for AED attendance. A high albumin level $(\mathrm{OR}=0.957$; 95\% CI, 0.935-0.980; $\mathrm{P}=0.001)$ and living alone (OR=0.677; 95\% CI, 0.473-0.969; $\mathrm{P}=0.033$ ) were negative predictors for AED attendance (Table 4). Overall, 310 (28.4\%) subjects had no reduction in bed days when comparing 6 months before and 6 months after joining the ICDS. Increasing age $(\mathrm{OR}=1.019$; 95\% CI, 1.002-1.036; $\mathrm{P}=0.025)$ and increasing number of medications (OR $=1.062$; 95\% CI, 1.0201.105; $\mathrm{P}=0.003)$ were significant independent positive predictors of no reduction in bed days; while higher haemoglobin level (OR=0.931; 95\% CI, 0.8710.995; $\mathrm{P}=0.034$ ) was a negative predictor (Table 4).

In HKWC, the cost per patient day was

TABLE 3. Number of AED attendances, unplanned acute hospital admissions, and hospital bed days (acute and convalescence) 6 months before and after joining the ICDS programme

\begin{tabular}{|c|c|c|c|c|}
\hline & \multicolumn{2}{|c|}{ Mean \pm SD } & \multirow[t]{2}{*}{$\%$ Reduction } & \multirow[t]{2}{*}{$P$ value } \\
\hline & 6-Month pre-ICDS & 6-Month post-ICDS & & \\
\hline AED attendance & $2.0 \pm 1.4$ & $1.2 \pm 1.8$ & $40 \%$ & $<0.001$ \\
\hline Unplanned acute hospital admission & $1.7 \pm 1.1$ & $0.9 \pm 1.4$ & $47 \%$ & $<0.001$ \\
\hline Hospital bed days & $16.1 \pm 17.9$ & $11.1 \pm 20.2$ & $31 \%$ & $<0.001$ \\
\hline
\end{tabular}

Abbreviations: AED = Accident and Emergency Department; ICDS = Integrated Care and Discharge Support for elderly patients; $\mathrm{SD}=$ standard deviation 
TABLE 4. Results of univariate and multivariate analysis*

\begin{tabular}{|c|c|c|c|c|c|c|c|c|}
\hline & \multicolumn{4}{|c|}{ Any AED attendance 6 months after ICDS } & \multicolumn{4}{|c|}{ No reduction in bed days 6 months after ICDS } \\
\hline & Univariate odds & $P$ value & Multivariate odds & $P$ value & Univariate odds & $P$ value & Multivariate odds & $\mathbf{P}$ value \\
\hline Age (per year) & $1.022(1.006-1.039)$ & 0.006 & $1.019(1.002-1.036)$ & 0.025 & $1.010(0.992-1.027)$ & 0.286 & $1.019(1.002-1.036)$ & 0.025 \\
\hline Gender (male) & $1.280(1.009-1.624)$ & 0.042 & NS & - & $1.274(0.979-1.658)$ & 0.072 & NS & - \\
\hline Living alone & $0.589(0.417-0.833)$ & 0.003 & $0.677(0.473-0.969)$ & 0.033 & $0.771(0.523-1.138)$ & 0.190 & NS & - \\
\hline ICM programme & $1.280(1.007-1.628)$ & 0.017 & NS & - & 1.243 (0.954-1.619) & 0.107 & NS & - \\
\hline Home oxygen & $1.824(1.017-3.131)$ & 0.001 & NS & - & $1.082(0.582-2.011)$ & 0.802 & NS & - \\
\hline Tube feeding & $3.291(0.661-16.376)$ & 0.146 & NS & - & $0.838(0.168-4.173)$ & 0.829 & NS & - \\
\hline Foley catheter & $2.581(0.985-6.768)$ & 0.054 & NS & - & $1.363(0.539-3.449)$ & 0.513 & NS & - \\
\hline Wound & $1.163(0.443-3.053)$ & 0.758 & NS & - & $1.602(0.531-4.831)$ & 0.403 & NS & - \\
\hline $\mathrm{Bl}-20$ at start & $0.963(0.936-0.991)$ & 0.009 & NS & - & $1.004(0.973-1.036)$ & 0.804 & NS & - \\
\hline AMT at start & $0.931(0.881-0.985)$ & 0.012 & NS & - & 1.008 (0.949-1.072) & 0.791 & NS & - \\
\hline MFAC at start & $0.90(0.741-1.056)$ & 0.525 & NS & - & $0.984(0.904-1.070)$ & 0.701 & NS & - \\
\hline $\mathrm{CCl}$ & 1.209 (1.138-1.284) & $<0.001$ & $1.178(1.108-1.254)$ & 0.001 & $1.088(1.026-1.154)$ & 0.005 & NS & - \\
\hline Haemoglobin level & $0.899(0.847-0.966)$ & 0.001 & NS & - & $0.915(0.857-0.977)$ & 0.008 & $0.931(0.871-0.995)$ & 0.034 \\
\hline Albumin level & $0.944(0.923-0.966)$ & $<0.001$ & $0.957(0.935-0.980)$ & 0.001 & $0.979(0.956-1.002)$ & 0.078 & NS & - \\
\hline Creatinine level & $1.002(1.001-1.003)$ & 0.007 & NS & - & $1.001(1.000-1.003)$ & 0.060 & NS & - \\
\hline No. of medications & $1.137(1.017-3.271)$ & 0.044 & NS & - & $1.071(1.030-1.113)$ & 0.001 & $1.062(1.020-1.105)$ & 0.003 \\
\hline
\end{tabular}

Abbreviations: AMT = Abbreviated Mental Test; BI-20 = Barthel Index 20; CCI = Charlson Comorbidity Index; ICDS = Integrated Care and Discharge

Support for elderly patients; ICM = Integrated Care Model; MFAC = Modified Functional Ambulation Category scale; NS = not significant

* Data are shown as odds ratio (95\% confidence interval), unless otherwise specified

HK $\$ 4461$ for an acute-hospital medical bed and HK\$2237 in a convalescent hospital. Each AED attendance also incurred a cost of HK\$877. The average LOS in an acute medical ward at QMH was 2.4 days. The total number of bed days saved for acute hospitals were $(1.7-0.9) \times 1090 \times 2.4=2093$ days. In terms of acute-hospital bed days, the total cost-saving 6 months following ICDS compared with 6 months before was $2093 \times \$ 4461=$ HK\$9 336873 (around HK\$9.3 million). The total cost-saving for convalescent-hospital bed days in 6 months was $([16-11] \times 1090-2093) \times \$ 2237=$ HK\$7 509609 (around HK\$7.5 million). The cost-saving due to reduced AED attendance was (2.0-1.2) x $1090 \mathrm{x}$ $\$ 877=$ HK\$764 744 (around HK\$0.76 million). The annual expenditure for the ICDS was HK\$12.62 million in total, giving a net cost-saving over 6 months of $(9.3+7.5+0.76)-12.62 / 2=$ HK\$11.25 million. The potential annual cost-saving was thus HK\$11.25 million $\times 2=H K \$ 22.5$ million (approximately US $\$ 2.9$ million).

\section{Discussion}

This study demonstrates that the present ICDS in HKWC reduces AED attendance, hospital admissions, and hospital bed days. A local study has shown that medical patients are in general prone to institutionalisation following discharge from hospital. ${ }^{18}$ This programme appeared to keep older patients at home as evidenced by the low institutionalisation rate (2.4\%). Nonetheless there was selection bias as those who required RCHE admission direct from hospital were excluded from the study. Hence, ICDS provided intervention in a group of older patients who had no imminent need of institutionalisation at the time of hospital discharge.

Different strategies have been described to reduce readmissions, namely geriatric assessment, discharge planning, a case manager approach, postdischarge support services, early intervention for ad-hoc medical problems, and use of telephone nursing services. ${ }^{6-11}$ One important element of success is a targeted approach that provides services to high-risk patients. ${ }^{12}$ In 2010, the Cochrane Database of Systematic Reviews revealed that a structured discharge plan tailored to the individual patient was likely to reduce hospital LOS and readmission rates for older people..$^{19}$ The efficacy of a post-discharge programme that comprises the above elements was supported by another meta-analysis. ${ }^{20}$ The ICDS in HKWC comprises all the above elements with a targeted approach that focuses on high-risk older patients as identified by their HARRPE score. In addition, high-risk older patients who were not identified by a HAPPRE score were recruited as a result of link nurse screening and clinical referrals in hospital.

Older patients recruited in the ICDS with motor and functional problems underwent $\mathrm{PT}$ and OT assessment during home visits. Home exercise 
could be taught as appropriate with selected patients referred to the geriatric day hospital for rehabilitation. This may help explain why the ICDS was able to improve the functional and ambulatory status of patients. We observed no significant AMT change in our recruited patients upon closure of ICDS. The ICDS aims at maintaining older patients in the community during the high-risk period rather than improving their cognitive function.

Multivariate analysis revealed that increasing age, low albumin level, and high CCI score were associated with AED attendance 6 months after joining the ICDS. This result was very similar to that of a systematic review of the general risk factors for preventable readmissions. ${ }^{21}$ It concluded that increasing age and poor health as measured by CCI were associated with high readmission risk. ${ }^{21}$ Low serum albumin level is known to associate with poorer clinical and rehabilitation outcomes in older patients. ${ }^{22}$ In this study, patients with advanced age, low albumin level, and high CCI score were more likely to attend AED again, even after joining the ICDS programme. Based on these results, we may consider adjusting our programme to target these 'ultra high-risk' groups. In this study, living alone was a protective factor for AED attendance 6 months after joining the ICDS. Although previous studies showed that living alone was a risk factor for hospital admission, we found that this group of patients had significantly fewer AED attendances after ICDS. ${ }^{23,24}$ Indeed, age, albumin level and CCI were all better in the living alone group compared with those who were not. Living alone remained a protective factor after multivariate analysis with the above-mentioned factors adjusted, indicating that it was an independent predictor by itself. There are several possible explanations for this observation. First, older people living at home alone belong to a selected group who are usually more self-reliant. With home visits and telephone support by ICDS case managers or HST, together with geriatrician backup, they have a dependable team from whom advice can be sought for ad-hoc problems. On the contrary, those living with their family might be less independent. Their health-seeking behaviour is strongly influenced by family members or carers at home, who may prompt them or bring them to the AED for urgent consultations.

In this study, there was a group of patients for whom there was no reduction in bed days 6 months after joining the ICDS. These patients were in more advanced age, with a low haemoglobin level, and prescribed an increasing number of drugs. It is possible that the outcome of the ICDS may be further improved by correcting the anaemia and reducing polypharmacy in this group of older patients.

There were several limitations in this study. The study was not a randomised controlled trial. The
ICDS programme is a government-funded service provided to all suitable older patients in Hong Kong. Hence, it was practically impossible to have a control group in the study. Bias in determining patients' discharge time might occur as there was no blinding of treating doctors in the programme. The decision and time to discharge was subjective and could have been affected by health care workers who wanted the programme to demonstrate beneficial results. The link nurses in the programme could not perform discharge planning in $100 \%$ of the admitted high-risk patients, as their service was limited on public holidays and Sundays. In addition, only $16.3 \%$ of patients were recruited to the programme after discharge planning. These factors might have led to selection bias in the study. Seasonal variation in hospital admissions among high-risk older patients might also affect the validity of the results. Nonetheless, our patients joined the ICDS at different time points during recruitment and this, to a certain extent, may minimise the seasonal variation effect on hospital admission analysis. Statistically, no adjustment was made for AED attendance and hospital admissions for patients who were institutionalised or who died during the post6-month period. The reduced number of patients due to deaths was also not considered during the end of study analysis. The appropriate analysis would use Cox's regression, making use of the time to event (AED attendance), and subjects who died or were institutionalised during the follow-up period would be censored and not just excluded from the analysis. Since the index admission was counted as the pre-ICDS period, unplanned admission during the pre-ICDS period would start from 'one', putting the performance during that period at a great disadvantage when compared with the post-ICDS period. This study only looked at patients admitted to hospitals in HKWC. This limited the generalisability of the results of ICDS in other clusters. The CCI used in this study was quantified based on ICD coding in CMS and might have led to undercoding and consequent underestimation of CCI for patients. Although there was a potential annual cost-saving of HK\$22.5 million with the ICDS, this was just a crude calculation and saving based on reduced bed days: reduced AED attendance provided a nominal saving. There was no actual reduction in staff requirements and other expenses as a result of reduced admissions. In addition, we did not consider planned readmissions that also contributed to health care expenditure. The ICDS is designed to prevent unplanned readmission. The ICM case managers and HST rarely interfere with planned readmission for patients, apart from reminding them to follow the schedule. Thus, analysis of the planned readmissions might not have impacted greatly on our study findings. 


\section{Conclusion}

The ICDS reduces AED attendance, unplanned acute hospital admissions, and hospital bed days in highrisk older patients. Additional studies are suggested to determine whether further reductions can be achieved by modifying some of the predictive factors identified in this study. A more detailed auditing is also warranted to demonstrate the value of ICDS in reducing health care costs.

\section{References}

1. Gordon A. 'Revolving door syndrome'. Elder Care 1995;7:9 10,12 .

2. Jencks SF, Williams MV, Coleman EA. Rehospitalizations among patients in the Medicare fee-for-service program. N Engl J Med 2009;360:1418-28.

3. Balla U, Malnick S, Schattner A. Early readmissions to the department of medicine as a screening tool for monitoring quality of care problems. Medicine (Baltimore) 2008;87:294-300

4. Wong EL, Cheung AW, Leung $\mathrm{MC}$, et al. Unplanned readmission rates, length of hospital stay, mortality, and medical costs of ten common medical conditions: a retrospective analysis of Hong Kong hospital data. BMC Health Serv Res 2011;11:149.

5. Luk JK, Tuet OS, Chan FH. Unplanned readmission among older medical patients discharged from an extended care hospital. International Hospital Federation Convention; 2001 May 15-18; Hong Kong.

6. Luk JK, Or KH, Woo J. Using the comprehensive geriatric assessment technique to assess elderly patients. Hong Kong Med J 2000;6:93-8.

7. Naylor MD, Brooten D, Campbell R, et al. Comprehensive discharge planning and home follow-up of hospitalized elders: a randomized clinical trial. JAMA 1999;281:613-20.

8. Hyde CJ, Robert IE, Sinclair AJ. The effects of supporting discharge from hospital to home in older people. Age Ageing 2000;29:271-9.

9. Phillips CO, Wright SM, Kern DE, Singa RM, Shepperd $S$, Rubin HR. Comprehensive discharge planning with postdischarge support for older patients with congestive heart failure: a meta-analysis. JAMA 2004;291:1358-67.

10. Steward S, Pearson S, Horowitz JD. Effects of a homebased intervention among patients with congestive heart failure discharged from acute hospital care. Arch Intern Med 1998;158:1067-72.
11. Lim WK, Lambert SF, Gray LC. Effectiveness of case management and post-acute services in older people after hospital discharge. Med J Aust 2003;178:262-6.

12. Coleman EA, Parry C, Chalmers S, Min SJ. The care transitions intervention: results of a randomized controlled trial. Arch Intern Med 2006;166:1822-8.

13. Chan S, Kwong P, Kong B, et al. Improving Health of High Risk Elderly in the Community-the HARRPE. Proceedings of the Symposium on Community Engagement III "Creating a Synergy for Community Health" 2008; Hong Kong. Hong Kong: Hong Kong Hospital Authority; 2008.

14. Ng MF, Sha KY, Tong BC. Bridging the gap: win-win from Integrated Discharge Support for Elderly Patients. HA Convention; 2011.

15. Chan TC, Luk JK, Chu LW, Chan FH. Validation study of Charlson Comorbidity Index in predicting mortality in Chinese older adults. Geriatr Gerontol Int 2013;14:452-7.

16. Chu LW, Pei CK, Ho MH, Chan PT. Validation of the Abbreviated Mental Test (Hong Kong version) in the elderly medical patients. Hong Kong Med J 1995;1:207-11.

17. Mahoney FI, Barthel DW. Functional evaluation: The Barthel index. Md State Med J 1965;14:61-5.

18. Luk JK, Chiu PK, Chu LW. Factors affecting institutionalization in older Chinese patients after recovery from acute medical illnesses. Arch Geront Geriatr 2009;49:e110-4.

19. Shepperd S, McClaran J, Phillips CO, et al. Discharge planning from hospital to home. Cochrane Database Syst Rev 2010;(1):CD000313.

20. Fox MT, Persaud M, Maimets I, Brooks D, O’Brien K, Tregunno D. Effectiveness of early discharge planning in acutely ill or injured hospitalized older adults: a systematic review and meta-analysis. BMC Geriatr 2013;13:70.

21. Vest JR, Gamm LD, Oxford BA, Gonzalez MI, Slawson KM. Determinants of preventable readmissions in the United States: a systematic review. Implement Sci 2010;5:88.

22. Luk JK, Chiu PK, Tam S, Chu LW. Relationship between admission albumin levels and rehabilitation outcomes in older patients. Arch Gerontol Geriatr 2011;53:84-9.

23. Arbaje AI, Wolff JL, Yu Q, Powe NR, Anderson GF, Boult C. Postdischarge environmental and socioeconomic factors and the likelihood of early hospital readmission among community-dwelling Medicare beneficiaries. Gerontologist 2008;48:495-504.

24. Hanania NA, David-Wang A, Kesten S, Chapman KR. Factors associated with emergency department dependence of patients with asthma. Chest 1997;111:2905. 